\title{
Desenhos animados em sala de aula: Tom e Jerry e Bob Esponja Calça Quadrada, uma análise comparativa
}

Rosana Fachel de Medeiros*

Resumo: Esse texto propõe uma análise comparativa entre duas animações destinadas ao público infantil: Tom e Jerry (1940) e Bob Esponja Calça Quadrada (1999), que apesar de serem produções de épocas e configurações sociais distintas são igualmente apreciadas pelas crianças. A partir desta constatação são apresentadas e analisadas as produções de sentido de uma turma de Educação Infantil frente a esses dois textos culturais.

Palavras-chave: Desenhos animados; Educação Infantil; Leitura de Imagens.

Abstract: This paper proposes a comparative analysis between two cartoons aimed at the child audience: Tom and Jerry (1940) and SpongeBob SquarePants (1999), that despite being products of different social settings and times are equally appreciated by children. From this observation are presented and analyzed the production of meaning in an Early Childhood Education class in front of these two cultural texts.

Keywords: Cartoon; Early Childhood Education; Reading Images.

Pedagoga Habilitada em Séries Iniciais e Educação Infantil. Especialista em Educação Infantil e Mestre em Educação e Artes Visuais pela UFRGS. Professora da Rede Pública de Ensino no município de Canoas. E-mail: zanafachel@hotmail.com 
Os desenhos animados estão presentes em minha vida desde a infância, lembro de acompanhar diariamente o Xou da Xuxa com a ansiedade de assistir a $A$ turma da pesada e a Caverna do Dragão. Naquela época as animações eram para mim simples entretenimentos. Tal visão somente mudou quando ingressei na Faculdade de Pedagogia na UFRGS, mais especificamente no $3^{\circ}$ semestre do curso ao tornar-me bolsista de Iniciação Científica no projeto de pesquisa As imagens e seus sentidos ${ }^{1}$ coordenado pela professora Dra. Analice Dutra Pillar, momento no qual tive a oportunidade de olhar criticamente para algumas das animações dirigidas ao público infantil. Após essa experiência, pensar sobre os desenhos animados tornou-se uma paixão.

Dessa forma, hoje, com o Mestrado concluído e sendo professora da rede pública de ensino na cidade de Canoas, ainda me instiga buscar entender a forma como as crianças percebem os desenhos animados e que relaçóes elas estabelecem a partir dessas produções.

Para tanto, selecionei o desenho animado Bob Esponja Calça Quadrada, escolha que se deu por três razões: a primeira, é o fato dessa animação ter sido meu objeto de estudo em um dos subprojetos que participei como bolsista e no Mestrado, pesquisa que originou a Dissertação intitulada Bob Esponja: produções de sentidos sobre infâncias e masculinidades.

Dentro desse projeto maior participei, no período de agosto de 2002 a dezembro de 2007, de três subprojetos: Regimes de visibilidade nos desenhos animados da televisão, que investigou os modos como os personagens dos desenhos se mostram. O corpus de análise foram os desenhos animados contemporâneos: A Vaca e o Frango, $O$ Laboratório de Dexter, As Meninas Superpoderosas, Jonnhy Bravo, Pokemón e Digimón. Procuramos, ainda, perceber a significação que crianças da Educação Infantil atribuíram a esses desenhos. O segundo subprojeto, O sincretismo nos desenhos animados da televisão, analisou as diferentes linguagens presentes nos desenhos animados $A$ Vaca e o Frango, O Laboratório de Dexter e As Meninas Superpoderosas. Investigamos, também, as leituras que crianças da $4^{a}$ série do Ensino Fundamental de uma escola púbica de ensino fizeram desses desenhos. O terceiro subprojeto foi Interação de linguagens no desenho animado Bob Esponja: Leitura, televisão e infância, onde buscamos entender como os sistemas visual e sonoro estão relacionados nesse desenho e como crianças da Educação Infantil e da $4^{\mathrm{a}}$ série do Ensino Fundamental o compreendem. 
A segunda nasceu no momento de arguição da Dissertação quando a banca incentivou-me a continuar pesquisando este desenho animado devido à sua riqueza audiovisual e temática. A indiscutível qualidade de Bob Esponja Calça Quadrada se dá por vários motivos, dentre os quais destaco a forma contemporânea como a animação apresenta as infâncias e os gêneros masculino e feminino. Ao retratar as infâncias o autor dá visibilidade ao enfraquecimento das fronteiras que na modernidade separavam o mundo infantil da idade adulta tendo em vista que os personagens principais assumem concomitantemente atitudes adultas e infantis. Essa ambiguidade também está presente na forma como os gêneros masculino e feminino são figurativizados. Os personagens masculinos assumem alguns comportamentos considerados do sexo feminino como a sensibilidade, a compaixão e o cuidado, enquanto a personagem feminina que mais se destaca mostra-se forte, corajosa, inteligente e habilidosa. Adjetivos que na nossa cultura são relacionados aos homens e não às mulheres (MEDEIROS, 2010).

A terceira razão para a escolha dessa animação foi meu desejo de estudar comparativamente duas animações e, para tanto, achei fundamental que fossem animaçôes que eu já conhecesse bem.

Como Bob Esponja é uma animação contemporânea resolvi selecionar uma animação mais antiga. Com o objetivo de aumentar as possibilidades de comparaçốes entre as duas e perceber se ambas são apreciadas pelas crianças.

Com esses critérios como pré-requisitos fiquei entre as animações Pica-pau e Tom e Jerry, acabando por optar pela segunda. Uma das razões desta escolha foi o fato de o texto cultural Picapau já haver sido objeto de estudo de uma pesquisadora renomada ${ }^{2}$. No entanto, foi decisivo o fato de em Tom e Jerry serem raros os momentos em que se ouvem as vozes dos personagens

2 O Pica-pau: herói ou vilão? Representação social da criança e reprodução da ideologia dominante (1985) de Elza Dias Pacheco. Nessa pesquisa e em outras que Pacheco realizou após a conclusão do seu curso de Doutorado a autora leva a criança e o desenho animado para o centro das discussões acadêmicas sobre mídia e educação. 
título e como em Bob Esponja, ao contrário, há muitos diálogos, acreditei que esse seria um importante e interessante aspecto para a análise comparatista entre as duas produções.

A opção por analisar comparativamente duas animações de diferentes épocas se deu pelo fato de eu acreditar que os cinquenta anos que as separam no tempo possibilitariam um maior número de comparaçốes entre as duas. Já que são grandes as mudanças nesse período de tempo especialmente em relação aos recursos tecnológicos infinitamente maiores nos anos dois mil. Nessas cinco décadas foram significativas também às transformações em relação à sociedade, como a revolução sexual na década de 60 e as mudanças na constituição das famílias, por exemplo.

Após a escolha das animaçóes passei a focalizar meu olhar em seus episódios com o intuito de selecionar um episódio de cada animação para analisá-los mais detalhada e comparativamente.

Chegar a um único episódio de Bob Esponja dentre os tantos que conheço e entre os seis que "olhei atentivamente"3 (OLIVEIRA, 2001) no Mestrado não foi uma tarefa fácil. Então decidi selecionar um episódio referente a cada uma das temáticas que tratei na Dissertação.

Os episódios foram: Másculo mesmo sem casca, $O$ dia da foto e Beijos da vovó. O primeiro episódio apresentado às crianças foi Másculo mesmo sem casca, que discute quase exclusivamente os aspectos que tornam os homens másculos ou não, a partir do qual pensei as questões referentes às masculinidades contemporâneas. Em seguida à sua segunda exibição para as crianças ${ }^{4}$

3 De acordo com Ana Claudia Oliveira " [...] as imagens lutam primeiro para entrar na órbita do ver e depois para serem olhadas atentivamente [...] Objetivando a visão, os demais sentidos são convocados para atuarem juntos a fim de despertar a percepção do sujeito (2001, p. 5).

4 A pesquisa foi realizada no período de abril a junho de 2010 com 18 crianças. Em cada dia da pesquisa de campo eu apresentava uma animação para as crianças, e posteriormente, a partir de uma entrevista semi estruturada, fazia perguntas referentes ao desenho assistido para elas. Em seguida apresentava a animação novamente e perguntava aos alunos se elas queriam acrescentar mais algum comentário sobre a produção. 
percebi que esse episódio não lhes chamou a atenção e rendeu poucos comentários. Notei então minha falha na seleção desse texto cultural, pois uma discussão referente às masculinidades provavelmente renderia mais frutos se oportunizada a uma turma de adolescentes ou adultos, essa temática não está em foco com crianças tão pequenas. Assim, substituí o episódio Másculo mesmo sem casca por Nana neném conchinha o qual também discute a masculinidade, mas agrega a tal discussão questões referentes à família, ao cuidado e às questões de gênero.

$O$ dia da foto foi selecionado para pensar sobre os elementos das animações que acarretam o riso e Beijos da vovó para discutir as questões referentes às infâncias.

Enquanto eu apresentava os episódios selecionados para as crianças, pensava em qual dos três episódios iria escolher para a análise comparativa e qual seria a aventura de Tom e Jerry que iria se vincular a pesquisa. Dessa forma, em meio à coleta de dados assistia aos episódios de Tom e Jerry à procura de uma animação que fosse enriquecer a análise comparativa. Felizmente essa procura acabou mais cedo do que eu esperava já que a segunda animação do DVD Tom e Jerry em grandes perseguições, Bebezinho, capturou meu olhar em decorrência das possíveis comparações e aproximações que poderia realizar entre este episódio e Nana neném conchinha, de Bob Esponja. Uma vez que os dois textos culturais trazem como uma das discussões o cuidado de bebês, sendo o bebê figurativizado na primeira animação por Tom.

$\mathrm{Na}$ animação Bebezinho Tom é tratado como bebê por sua dona. Ela coloca uma fralda no gato, o alimenta com a mamadeira e o deita em um berço, tal situação faz com que Jerry e os gatos da vizinhança se divirtam as suas custas. No episódio de Bob Esponja, o bebê é uma concha do mar. Bob Esponja e Patrick encontram o bebê concha no chão e o levam para dentro do abacaxi para cuidá-lo, para tanto decidem que Bob será a mãe e Patrick o pai da conchinha. 
Por acreditar que o episódio de Tom e Jerry proporcionaria comparações interessantes com a animação Nana neném conchinha sequer apresentei a aventura Beijos da vovó para as crianças.

Selecionados os episódios passarei agora à análise comparativa, fazendo uso do "olhar pensante" (MARTINS, 1993) para estudar os dois episódios selecionados e buscando entender a forma como as crianças da Educação Infantil produzem sentidos frente a essas produçôes.

\section{As animações: Tom e Jerry e Bob Esponja}

Tom e Jerry é uma produção estadunidense da década de quarenta dirigida por Bill Hanna e Joseph Barbera, que juntos criaram a empresa de desenhos animados Hanna Barbera, por essa animação seus criadores ganharam sete Óscares e oito Emmy - prêmio americano para os programas veiculados na televisão. Tom e Jerry é veiculado no canal de TV a cabo Cartoon Network de segunda-feira a sábado em dois horários diferentes e também na televisão aberta no programa Carrossel animado do canal 5 (SBT) de segunda-feira à sexta-feira. A animação centra-se nas tentativas, na maioria das vezes frustradas, de Tom capturar Jerry e nas destruições causadas por estas. Tom raramente consegue apanhar Jerry, principalmente por causa das habilidades do rato e também devido à sua própria estupidez. As perseguições são sempre eletrizantes e acompanhadas por ótimas trilhas sonoras. O diretor de música Scott Bradley criou obras interessantes que misturavam jazz, música clássica e música pop. Outro personagem que marca persença em vários episódios de Tom e Jerry é o cão bullgog Spike, que em muitas aventuras ajuda Jerry a escapar de Tom. Tom e Jerry vivem em uma casa bem confortável, Tom é o gato de estimação da família e Jerry é o hospede inconveniente que vive em uma toca dentro de uma das paredes da casa.

5 De acordo com Miriam Celeste Martins o olhar pensante diz respeito ao olhar sensível que é afetivo. É aquele olhar que aprecia, pensa, reflete, interpreta, avalia e julga. 
Bob Esponja Calça Quadrada (SpongeBob SquarePants) foi criado em 1999 por Stephen Hillenburg nos Estados Unidos. Atualmente é veiculado pela TV a cabo (Nickelodeon) de segunda-feira à sexta-feira em diferentes horários e pela TV aberta, no programa $T V$ Globinho da Rede Globo (canal 12), no programa Sessão Galerinha no Canal ULBRA TV (canal 48) e nos fins de semana na TV Cristal/Rede Brasil (canal 55) no programa Manhã criança.

O desenho animado é ambientado numa cidade submarina chamada Fenda do Bikini, localizada no Oceano Pacífico. Essa cidade supostamente se localiza no Atol ${ }^{6}$ de Bikini que faz parte da República das Ilhas Marshall ${ }^{7}$. O personagem título do desenho mora na Rua das Conchas, 124, em um abacaxi, com seu bichinho de estimação, um caramujo-marinho chamado Gary Caracol. Bob Esponja trabalha como cozinheiro na lanchonete O Siri Cascudo. Quando ele não está atormentando seu vizinho mal-humorado Lula Molusco, está no meio de alguma encrenca com o seu melhor amigo Patrick Estrela, ou com sua amiga Sandy Bochechas.

Bob Esponja Calça Quadrada já foi agraciado com seis Emmy. De acordo com a revista Times, Bob Esponja Calça Quadrada está entre os 100 melhores programas de TV de todos os tempos ${ }^{8}$. A animação é transmitida em 170 países, em 29 línguas diferentes. Em 2009, Bob Esponja já contava com 125 episódios? $\mathrm{O}$ sucesso e a popularidade do desenho proporcionaram a seu criador o $54^{\circ}$ lugar na lista das pessoas mais ricas do mundo.

6 Denomina-se Atol a ilha ou a cadeia de ilhas em forma de anel formada por recifes coralinos que possuem uma lagoa com comunicação para o mar em seu interior. Os atóis são mais frequentes nos mares tropicais do Oceano Pacífico e Índico.

7 Informação capturadas dos endereços eletrônicos: http://pt.wikipedia.org/wiki/Atol de_bikini acessado em 18 out. 2007. E http://veja.abril.com.br/121108/p_138a. shtml e http://www.natgeo.com.br/especiais/de-volta-a-bikini/ acessados em: 27 dez de 2009.

8 http://tv.globo.com/ENT/Tv/Seriados/Lost/0,,AAl630380-6258,00-REVISTA+ TIME+ELEGE+OS+MELHORES + PROGRAMAS +DE+TV+DE+TODOS +OS+TEMPOS.html acessado em: 01 out. 2008.

9 O desenho animado Mickey Mouse (1928) levou 50 anos apara chegar a esse número de episódios produzidos. 
A semelhança entre as duas animações inicia no sucesso de ambas, coroado pelo o número de prêmios que receberam, e continua no fato de os personagens principais de ambas as animações serem animais humanizados: Bob é uma esponja-domar, Patrick uma estrela-do-mar, Tom é um gato e Jerry um rato, mas eles se vestem, caminham, tem sentimentos e se alimentam como as pessoas, apresentando assim uma visão antropocêntrica da natureza.

As aproximações não param por aí, nos dois desenhos os personagens principais são figurativizados por uma dupla de animais do sexo masculino na qual um é mais esperto do que o outro. Assim, Tom cai facilmente nas armações de Jerry e Patrick é convencido sem esforço por Bob Esponja a fazer parte de suas aventuras.

As diferenças entre as animações começam nas moradias dos personagens: Bob e Patrick moram sozinhos, um em um abacaxi e outro embaixo de uma pedra; já Tom mora em uma casa de classe média, pois é o bicho de estimação de uma menina, e Jerry mora em uma toca na mesma casa.

Outro aspecto que chama a atenção são os efeitos sonoros presentes nas duas animações Bob Esponja apresenta uma riqueza de ruídos e sons diversos, além de ótimas músicas com a participação de bandas famosas como Pantera. Os diálogos são diversos e envolvem diferentes assuntos como: paternidade, maternidade, ser criança, ser adulto, trabalho, entre outros. Em Tom e Jerry as músicas também são variadas e de boa qualidade, os ruídos não são muito diversificados, na maior parte dos episódios eles se limitam aos barulhos oriundos das perseguiçôes de Tom a Jerry, como a quebra de um móvel, ou de uma janela de vidro. Os diálogos são escassos, são raras as vezes em que se ouve a voz de Tom ou de Jerry. A maior parte das narrativas é contada pela sequência de imagens e de sons, os quais direcionam o olhar do espectador para a história apresentada e é comum a participação de um narrador quando os episódios são estrelados somente por Tom e Jerry. 
Em Bob Esponja há um narrador com sotaque francês. Sua participação se limita aos instantes iniciais de alguns episódios situando a narrativa, ou durante determinadas aventuras para marcar a passagem de tempo.

As temáticas dos episódios diferem bastante. Em Tom e Jerry a maior parte das narrativas gira em torno das caças de Tom a Jerry e das diferentes armadilhas que ele cria para capturá-lo. Os episódios geralmente terminam com Tom arrasado por sua incompetência, ou ainda com os dois magoados. Como ocorre em Bebezinho onde no fim do episódio Jerry da gargalhadas, pois a dona de Tom o obrigou a tomar castor oil (óleo de rícino), mas logo em seguida o acontecimento perde a graça, pois uma gota do óleo pinga em sua boca.

Em Bob Esponja essas perseguições não acontecem já que os personagens principais são grandes amigos, mesmo em episódios que os dois competem entre si como em Os jogos do mestre cuca, ou brigam como em Nana neném conchinha esse mal entendido não dura até o fim da trama, pois os dois sempre se dão conta do quanto se gostam e voltam a ser amigos.

\section{Os episódios: O Bebezinho e Nana neném conchinha}

O Bebezinho (Baby Puss, 1943), de Tom e Jerry, e Nana neném conchinba (Rock-a-bay bivalve, 2002), de Bob Esponja. A aproximação entre os dois episódios já se apresenta em seus títulos, que anunciam a temática comum a ambas as narrativas, os bebês e os cuidados que necessitam. No primeiro, Tom é tratado como bebê por sua dona, fato que transforma-se em motivo de piada para Jerry e os gatos da vizinhança. Em Nana neném conchinha, Bob e Patrick encontram um bebê conchinha e decidem cuidar dele, para tanto, um faz o papel de mãe e o outro de pai. 
O que também se repete nos desenhos é a música Rock-aBye Baby ${ }^{10}$, um clássico do cancioneiro infantil estadunidense. $\mathrm{Na}$ aventura estrelada por Bob e Patrick essa música está na abertura do episódio de forma instrumental, já na outra animação a canção está presente em diferentes momentos algumas vezes apenas instrumental e em outras também cantada, sendo em dado momento cantada pelos gatos da vizinhança quando eles observam Tom deitado no berço de touca e de babeiro, tomando mamadeira.

Nos dois episódios o que também se repete são personagens do sexo masculino vestindo roupas e adereços do sexo feminino, como chapéu, saia, brincos, batom, salto alto. Em Nana neném conchinha é Bob Esponja quem aparece vestido de mulher na hora em que ele e Patrick decidem passear como o bebê conchinha e no momento em que Patrick chega de madrugada em casa Bob está com rolos no cabelo.

Já em Bebezinho dois personagens são mostrados utilizando indumentária feminina. Jerry, quando tenta enganar Tom e fugir dele, saí de dentro da casa de boneca vestido de mulher. E um dos três gatos da vizinhança que foram até a casa chamados por Jerry. Quando os três se dão conta do constrangimento pelo qual Tom estava passando, o ridicularizam ainda mais cantando uma canção de ninar para ele e trocando a sua fralda. Para ironizar a situação um dos gatos com o auxílio de seus companheiros canta também a música Mamãe en quero sucesso interpretado por

\footnotetext{
10 Letra da canção de ninar Rock-a-Bye Baby, de autor desconhecido:

Rock-a-bye baby, in the treetop

When the wind blows, the cradle will rock

When the bough breaks, the cradle will fall

And down will come baby, cradle and all

Baby is drowsing, cozy and fair

Mother sits near, in her rocking chair

Forward and back, the cradle she swings

And though baby sleeps, he hears what she sings

From the high rooftops, down to the sea

No one's as dear, as baby to me

Wee little fingers, eyes wide and bright

Now sound asleep, until morning light
} 
Carmen Miranda. Nesse momento um dos gatos personifica a artista e é mostrado com todos os adereços que eram utilizados pela cantora em suas apresentações.

Na época em que a animação Tom e Jerry foi produzida situações nas quais os homens apareciam vestidos como mulheres tinham como efeito de sentido a comicidade. Como é muito bem retratado na produção Quando mais quente melhor (1959). Nesse filme dois músicos, Joe e Jerry, presenciam um massacre, para fugir dos assassinos eles se disfarçam e entram em uma banda só de mulheres, a qual está indo para Miami fazer shows. Nessa produção o efeito de humor proporcionado por dois personagens do sexo masculino vestidos como mulheres já se evidenciava pela classificação do filme como comédia. E continua ao longo da trama com as dificuldades sentidas pelos dois em se caracterizarem e agirem como mulheres. Nessa comédia a sexualidade dos personagens em momento algum é colocada à prova, já que mesmo vestidos de mulheres os dois demonstram atração pelo sexo oposto e um deles se apaixona pela cantora da banda.

Em Bob Esponja essa caracterização de Bob Esponja como mulher transcende a comicidade já que ele além de aparecer vestido com roupas e acessórios femininos exerce o papel socialmente atribuído as mulheres como o de serem ótimas cuidadoras e excelentes donas de casa. Dessa forma, no mesmo momento que essa produção chama atenção para diferentes constituições familiares ela reforça o estereótipo da mulher como mãe e rainha do lar além de dar margem a uma discussão sobre a sexualidade dos personagens.

Nos dois episódios, mesmo com a familiaridade entre as temáticas pode-se notar uma grande diferença na forma como ela é abordada. Em Bob Esponja além de ser discutido o cuidado dos bebês também é tratada as questões de gênero e os laços familiares. No episódio Nana neném conchinha, os personagens principais acreditam ser conveniente a constituição de uma família para o cuidado do bebê. Assim, Bob faz o papel da mãe e 
é responsável pelo cuidado da criança e da casa e Patrick do pai, sendo ele quem trabalha fora.

No episódio Bebezinho não há a constituição de uma família, mas o cuidar é retrado na relação da menina com seu animal de estimação, o qual é tratado por ela como um bebê. Figurativizando assim mais uma brincadeira infantil do que uma relação familiar. Dessa forma pode-se pensar que a animação estrelada por Bob e Patrick, de certa forma, evidencia a variada constituição familiar com a qual convivemos na atualidade e a animação Bebezinho, em contrapartida, reforça a realidade cultural de sua época e apresenta o estereótipo feminino de maternidade, no qual desde pequenas as meninas são treinadas para exercerem seu papel de mãe e dona de casa.

Além de serem evidentes essas diferenças em relação ao plano do conteúdo ${ }^{11}$ pode-se observar algumas distinções também em relação ao plano da expressão ${ }^{12}$ tendo em vista que em Tom e Jerry há pouca variação de cores e um predomínio de cores claras. Em Bob Esponja existe uma variedade de cores e a maioria delas em tons mais chamativos. Nos episódios dessas duas animações a que tive acesso pude perceber que em Tom $e$ Jerry há o predomínio da cor cinza em diferentes tonalidades, em Bob Esponja nota-se que a cor azul está presente em todos os episódios figurativizando assim o fundo do mar. Outra evidente diferença entre as duas animações.

A maior parte das aventuras estreladas por Tom e Jerry acontecem no interior ou no quintal da casa onde Tom mora. Já em Bob Esponja os episódios se passam nas profundezas do Oceano Pacífico. Dessa forma todos os personagens que estrelam o desenho animado Tom e Jerry são animais terrestres. Em Bob Esponja a maior parte dos personagens são animais marinhos, com exceção da personagem Sandy Bochechas, que é um esquilo

\footnotetext{
11 O plano do conteúdo diz respeito a história que está sendo apresentada e é o lugar do significado, dos julgamentos e atitudes, das práticas linguísticas de cada época, grupo, de cada pessoa.

12 Dá conta das características físicas da imagem, suas cores, suas formas, seu espaço e a sua materialidade (FLOCH, 2001).
} 
fêmea que vive no fundo do mar utilizando uma roupa especial ou dentro de sua casa a qual é protegida por uma redoma de poliuretano $^{13}$ reforçada, e dos super - heróis Homem Sereia e Mexilhãozinho que são humanos.

$\mathrm{O}$ número de personagens presentes em cada uma das animações também diferem bastante. Enquanto em Tom e Jerry a maior parte das narrativas é estrelada somente pelos dois, outra parte dos episódios conta com a participação do cão Spike, poucos são os episódios que aparecem outros personagens. Já em Bob Esponja somente alguns episódios centram-se apenas nos personagens principais, na maioria há participação de vários outros personagens, como: Sandy, Sr. Siriqueijo, Sra Puff e Lula Molusco.

\section{As leituras das crianças}

As questões referentes às semelhanças e diferenças entre as duas animações selecionadas para esse estudo comparativo não estiveram em pauta nas leituras das crianças. $\mathrm{O}$ que mais se evidenciou foram comentários relativos às questões de gênero, mais especificamente à consolidação dos estereótipos socialmente atribuídos para os gêneros masculino e feminino.

$\mathrm{Na}$ análise das falas das crianças foi interessante perceber o quanto elas aceitam e reforçam os estereótipos. Assim, tudo o que fugiu dos comportamentos socialmente atribuídos aos homens e às mulheres causou estranhamento ou tornou-se engraçado para elas. Essa constatação não me surpreendeu já que de acordo com Meyer e Soares:

[...] as escolas [a mídia, a família] podem ser um exemplo de instituição em que se reitera, constantemente, aquilo que é definido como norma central, já que norteiam [...] suas práticas a partir de um padrão único (2008, p. 11).

13 Conforme Sandy Bochechas, no episódio Chá em terra firma "[..] esse é o nome chique do plástico". 
As autoras apoiadas em Louro (2002) pontuam também que nessa instituição haveria somente um modo legítimo e natural de masculinidade e de feminilidade. Fugir desses padrões significa buscar o desvio, sair do centro. Assim, nas leituras das crianças se fez presente a legitimação dos comportamentos culturalmente aceitos para os indivíduos dos sexos masculinos e femininos. Esses estereótipos socialmente atribuídos aos homens e as mulheres foram reforçados em diferentes momentos de suas falas em relação a cada um dos episódios. Momentos que serão ilustrados agora com trechos de nossas conversas em relação aos dois episódios.

\section{Episódio Nana neném conchinha - Bob Esponja Calça Quadrada}

Pesquisadora: Que parte vocês mais gostaram?

"Eu gostei dele beijando o Bob daí ele [bebê conchinha] foi embora" $\left(\mathrm{R}^{14}\right)$

"Eles não se beijaram porque eles são guris" (N)

Pesquisadora: Será que existem guris que se beijam?

"Não!" [Todos juntos]

Pesquisadora: Que parte foi mais engraçada?

"Bob queria ser uma mamãe, achei engraçado quando ele se vestiu de mamãe" $(\mathrm{N})$

\section{Episódio Bebezinho Tom e Jerry}

Que parte vocês mais gostaram?

"Quando o rato saiu de mulher" (W)

"Eu gostei que o gatinho pequeno dançou que nem uma mulher, ele se vestiu e ainda botou batom" (N)

"O grande dançou que nem uma menina" (M)

$\mathrm{Na}$ análise das falas das crianças foi possível notar que os momentos que mais lhes divertiram e que mais geraram comentários foram aqueles em que os personagens masculinos foram mostrados em situaçóes, que, em certa medida, poderiam colocar

14 Para preservar a identidade das crianças deixei somente a letra inicial de seus nomes. 
a prova a masculinidade hegemônica: quando Bob, Tom e Jerry apareceram vestidos de mulher, em Nana neném conchinha e em Bebezinho, respectivamente, e no momento em que um dos gatos da vizinhança aparece vestido com os adereços de Carmen Miranda e imita sua maneira de dançar. As crianças também demonstraram não aceitar o fato de dois meninos se beijarem.

Ao apresentar essas produções para as crianças a minha intenção não foi a de chamar-lhes a atenção para as diferentes masculinidades e feminilidades com as quais estamos em contato na atualidade, mas buscar perceber as significações que elas iriam atribuir a essas produções a partir da oportunidade que lhes foi dada de pensar sobre o que veem. Na prática diária de sala de aula busco problematizar questões de gênero, mas essa não foi a intenção dessa etapa da pesquisa.

\section{Algumas considerações}

Analisar comparativamente estas duas animações destinadas ao público infantil, que conquistaram sucesso de público e continuam encantando as crianças, foi um desafio interessante e surpreendente. Em primeiro lugar por romper com minhas expectativas, pois eu acreditava que os cinquenta anos que separam as duas produções resultariam em mais diferenças do que semelhanças entre elas, mas isso não se confirmou.

Constatei que as animações apresentam diferenças como, as temáticas tratadas pelos episódios, o número de personagens, as cores mais vivas em Bob Esponja, os cenários, a escassez de falas em Tom e Jerry, contudo também apresentam semelhanças como o fato de serem ambas estreladas por uma dupla de animais machos, as duas são veiculadas em canais da televisão aberta e na TV a cabo e as produções são sucesso de público e encantam seus telespectadores diariamente.

Os dois desenhos animados, em certa medida, retratam as realidades culturais de suas épocas Tom e Jerry ao apresentar uma 
menina cuidando de seu gato como se fosse seu filho, reforça assim a forte relação enraizada em na sociedade da época da feminilidade com a maternidade. Já em Bob Esponja o que chama atenção é exatamente o oposto, ou seja, a quebra dos estereótipos, além disso, dá visibilidade as diferentes configurações da família contemporânea.

$\mathrm{Na}$ análise das falas das crianças o que pude comprovar foi que as diferenças e semelhanças presentes nas duas animaçôes não estiveram em pauta nas suas leituras, nem os conteúdos implícitos nos desenhos foram mencionados por elas. Isso se deve ao fato de crianças da Educação Infantil e dos Anos Iniciais do Ensino Fundamental muitas vezes não serem estimuladas a fazer relações e a pensar sobre o que veem, assim não é de se estranhar que a maior parte das significações atribuídas por elas seja embasada em conhecimentos socialmente construídos, especialmente em relação às questôes de gênero.

Dessa forma, a importância dessa pesquisa está no fato de propiciar às crianças um momento para falarem sobre as animações que veem diariamente pela televisão. Um desdobramento interessante desse estudo seria reapresentar as animações para as crianças incentivando-as a olhar as duas animações comparativamente e problematizar os estereótipos socialmente construídos em relação às questões de gênero.

Finalizo esse artigo defendendo a introdução de produtos da mídia televisiva dentro de sala de aula tendo em vista que:

[...] a televisão, com meio século de presença entre nós, compartilha com a escola e a família o processo educacional, tendo-se tornado um importante agente de formação. Ela até mesmo leva vantagem em relação aos demais agentes: sua linguagem é mais ágil e está muito mais integrada ao cotidiano: o tempo de exposição das pessoas à televisão costuma ser maior do que o destinado à escola ou à convivência com os pais (BACCEGA, p. 95, 2000).

Nessa mesma direção Rosa Fischer pontua que a televisão tem uma participação decisiva na constituição do sujeito contemporâneo de acordo com a autora: 
$[\ldots]$ modos de existência narrados através de sons e imagens $[\ldots]$ tem uma participação significativa na vida das pessoas, uma vez que de algum modo pautam, orientam, interpelam o cotidiano de milhões de cidadãos brasileiros - ou seja, participam da produção de sua identidade individual e cultural e operam sobre a constituição de sua subjetividade (FISCHER, 2001, p. 16).

Assim, oportunizar aos alunos situações de reflexão sobre o que assistem e sobre os ensinamentos que são oportunizados pela mídia televisiva é um momento importantíssimo de construção de conhecimento, pois quanto mais habituados a esse exercício mais competentes se tornarão para a compreesão e interpretação de qualquer imagem.

\section{Referências}

BACCEGA, Maria Aparecida. Comunicação/educação: aproximações. In: BUCCI, Eugenio. A tv aos 50 anos - criticando a televisão brasileira no seu cinqüentenário. São Paulo: Fundação Perseu Abramo, 2000.

CELESTE, Miriam. O sensível olhar-pensante: premissas para a construção de uma pedagogia do olhar. In: ARTEunesp, São Paulo, v. 9, p. 199-217, 1993.

FISCHER, Rosa. Televisão e Educação: Fluir e pensar a TV. Belo Horizonte: Autêntica, 2001.

FLOCH, Jean-Marie. Alguns conceitos em semiótica geral. Documentos de Estudo do Centro de Pesquisas Sociossemióticas. São Paulo: CPS, 2001.

MEDEIROS, Rosana Fachel de. Bob Esponja: produções de sentidos sobre infâncias e masculinidades. 2010. 130fs. Dissertação (Mestrado em Educação). Universidade Federal do Rio Grande do Sul, Porto Alegre, 2010.

MEYER, Dogmar Estermann; SOARES, Rosângela de Fátima Rodrigues. Corpo, gênero e sexualidade nas práticas escolares: um início de reflexão. In: MEYER, Dogmar Estermann e SOARES, Rosângela de 
Fátima Rodrigues. (Orgs). Corpo, gênero e sexualidade. Porto Alegre: Mediação, 2008.

OLIVEIRA, Ana Claudia de. Lisibilidade da imagem. Revista da Fundarte/v. 1, n. 1, jan./jun. 2001, p. 5-7 